\title{
Photosynthesis and sink size: An explanation for the low productivity of grass swards in autumn
}

\section{B. Deinum}

Department of Field Crops and Grassland Husbandry, Agricultural University, Wageningen, the Netherlands

Accepted: 9 November 1976

Key words: photosynthesis, ryegrass, Lolium multiflorum, Lolium perenne, defoliation, shading, soluble carbohydrate, vegetative growth, stomatal resistance, diffusion resistance

\section{Summary}

Results are presented of experiments on the effect of tiller manipulation on photosynthesis of ryegrass leaves.

It was demonstrated that defoliation and shading of the axillary tillers of vegetative plants stimulated leaf photosynthesis of the main shoot to the high level characteristic of leaves from reproductive plants. This high photosynthesis coincided with a lower stomatal and internal diffusion resistance and a lower content of soluble carbohydrate, suggesting that these stressed tillers function as sinks for assimilates.

From these results and from literature it was concluded that the lack of sinks and the poor light penetration into the region of leaf development in the crop are the major causes of the poor production of vegetative grass crops in late summer and autumn and some suggestions are made to improve dry matter production during this period.

\section{Introduction}

Grass production in the Netherlands and many other temperate regions is low during the second part of the growing season. It is not only lower than in spring but it also lags behind the productivity calculated on the basis of the solar irradiance (Alberda and Sibma, 1968) and coincides with a lower crop photosynthesis (Alberda, 1974; Leafe, 1972; Leafe et al., 1974). Since the crop is reproductive in spring and vegetative in the latter part of the season these differences in production and photosynthesis coincide with differences in the stage of development (Leafe et al., 1974; Behaeghe, 1974). This was also apparent in an experiment in late summer with Westerwolths ryegrass which showed a high rate of crop photosynthesis and a high production rate during stem elongation, whereas in the same experiment vegetative 
grasses showed lower photosynthesis and production (Deinum, 1972, unpublished data).

These differences appeared more closely related to individual leaf photosynthesis at light saturation than to crop structure, so it was suggested that the low photosynthesis of leaves in vegetative grass was the major cause of poor grass growth in late summer. Consequently the question arises whether photosynthesis is inherently low in the vegetative grass crop or whether it can be manipulated.

In this respect it may be suggested that the high photosynthesis in a reproductive crop is caused by the high demand for assimilates in the elongating stem and the growing inflorescence, whereas in late summer the vegetative tiller has no such demand, and is transferring assimilates not necessary for maintenance only into further leaf growth. If this is true, then photosynthesis might be stimulated by creation of additional sinks. Axillary tillers may be regarded in this way: they depend on the mother shoot during formation, but become progressively independent during their development, although the link between the two remains intact. So when one of the two is put under a stress the other is able to supply the stressed tiller with the essential nutrients (Clifford et al., 1973). That such a stressed tiller can be a sink for assimilates is shown by Gifford \& Marshall (1973) who found that leaf photosynthesis of the main shoot was increased by defoliation of the other tillers.

To test this hypothesis further and to see whether the low demand for assimilates is the real reason for a smaller dry-matter production in late summer three experiments were performed of which the results are presented in this paper.

\section{Materials and methods}

\section{Experiment 1. Effect of tiller manipulation on photosynthesis of leaves in controlled conditions}

On 18 December 1974 seeds of Lolium multiflorum cv. Milamo were sown in 5-litre plastic pots, filled with sandy soil, and placed in a temperature-controlled greenhouse at $15{ }^{\circ} \mathrm{C}$. After emergence plants were thinned to 5 per pot. Pots were kept well watered and adequately supplied with mineral nutrients.

Plants received about $80 \%$ of natural daylight supplemented with artificial light from HPLR-mercury lamps during 16 hours in such a quantity that average radiation was about $1000 \mathrm{~J} \mathrm{~cm}^{-2}$ day $^{-1}(400-1000 \mathrm{~nm})$.

Tillers were growing very prostrate in these conditions. Axillary tillers were cut to about $1 \mathrm{~cm}$ length at weekly intervals, and dying leaves on the main shoot were removed as well, leaving the rest of the main shoot intact. Two, one and zero weeks (treatment D, C and B, respectively) before the onset of photosynthesis measurement this cutting was stopped giving main shoots with long, medium and short tillers at the start of the measurements. In addition, in the treatment of medium tiller length the axillary tillers were placed in darkness by placing a black plastic pot upside down over the tillers with the main shoot protuding through a small hole (treatment A). Measurement of photosynthesis on the youngest fully expanded leaf of five main shoots per treatment were made daily for 4 consecutive days from 11-14 February. 
The same procedure was repeated 3 weeks later. Treatments are summarized in Table 1.

Experiment 2. Effect of tiller manipulation on photosynthesis of leaves in spaced plants in the field

This experiment was carried out to investigate whether the plants in the field would react in the same way as those in the glasshouse. It consisted of two groups of plants of Lolium multiflorum cv. Milamo. Seeds of one group were sown in Jiffy pots (size 7) and allowed to emerge in a greenhouse at about $15^{\circ} \mathrm{C}$, after which they were placed at $4{ }^{\circ} \mathrm{C}$ and $8 \mathrm{~h}$ daylength for 6 weeks to induce vernalization. Eight weeks later the second group of seeds was sown in similar pots and kept in the same greenhouse continuously to prevent vernalization. Both groups were planted in the field on 24 April 1975 at $50-\mathrm{cm}$ centres. The field was fertilized adequately and in dry weather it was irrigated. Plants were growing very prostrate again in this experiment. On 2 June the treatments as described in Table 1 were established. In this case the treatment with the long tillers in darkness (treatment E) was effected by placing a light tight highly reflecting mylar foil over the plant with the main tiller protuding through a small hole. Photosynthesis measurement were made on the youngest fully expanded leaf of four to five main shoots per treatment on 13 consecutive working days from 4 June until 20 June. The results of the weekly averages per treatment of 9-13 June and 16-20 June will be presented.

Table 1. Description of the treatments in the three experiments.

\begin{tabular}{lc}
\hline Code & Tiller description \\
& Experiment 1 \\
A & $6-12 \mathrm{~cm}$ axillary tiller length, grown in darkness \\
B & $0-6 \mathrm{~cm}$ axillary tiller length, grown in the light \\
C & $6-12 \mathrm{~cm}$ axillary tiller length, grown in the light \\
D & $15-20 \mathrm{~cm}$ axillary tiller length, grown in the light
\end{tabular}

\section{Experiment 2}

A Vernalized, but not yet elongating main shoot with long axillary tillers, grown in the light

B Vegetative main shoot with $0-4 \mathrm{~cm}$ long axillary tillers, clipped frequently, grown in the light

C Vegetative main shoot with axillary tillers only clipped on 2 June, and then allowed to regrow undisturbed in the light

D Vegetative main shoot with long axillary tillers, grown in the light

E Vegetative main shoot with long axillary tillers, grown in darkness

\section{Experiment 3}

A Crop left intact

B Individual plant with $0-4 \mathrm{~cm}$ axillary tillers, clipped frequently, grown in the light

C Individual plant with axillary tillers only clipped on 8 September and allowed to regrow undisturbed in the light

D Individual plant with long axillary tillers in the light

E Individual plant with long axillary tillers in darkness 
Experiment 3. Effect of tiller manipulation on photosynthesis of leaves in a grass crop in autumn

This experiment was carried out to see whether the phenomena found in the former experiments were also present in a pasture under conditions in which poor grass production is found.

A vegetative grass sward of a permanent pasture on a clay soil consisting for about $95 \%$ of Lolium perenne was fertilized and irrigated abundantly at the beginning of August 1975 to encourage maximum growth. On 8 September, when a crop of erect tillers of about $3000 \mathrm{~kg}$ dry matter per ha was present, the different treatments were established, as described in Table 1 . In treatment ' $A$ ' the crop was left intact. In the remaining treatments, plots with individual plants at about 5 per $\mathrm{m}^{2}$ were produced by clipping the neighbouring grass to ground level. Measurements of photosynthesis of youngest fully expanded leaves were made daily on 4 to 5 main shoots per treatment on 14 consecutive work-days from 9 to 26 September. The weekly averages of 15-19 September and 22-26 September will be presented.

\section{Measurement of photosynthesis}

In all cases, net photosynthesis was measured on the youngest fully expanded leaf attached to the main shoot. Transpiration was measured as well, so gas phase $\left(r_{a}+r_{s}\right)$ and internal resistance $\left(r_{i}\right)$ could be calculated. Gas phase resistance was calculated as the boundery layer $\left(r_{a}\right)$ plus stomatal resistance $\left(r_{s}\right)$, as described by Gifford \& Marshall (1973).

Photosynthesis and transpiration of the leaves was measured in an open system of long narrow leaf chambers. $\mathrm{CO}_{2}$ exchange was measured with an URAS infrared gas analyser and transpiration with an Aqmel dewpoint hygrometer. $\mathrm{CO}_{2}$ content of the ingoing air was maintained at about $320 \mathrm{~cm}^{3} / \mathrm{m}^{3}$ and water content was somewhat below that of outside air. Light intensity was measured with a Kipp solarimeter and leaf temperature with a copper-constantan thermocouple pressed against the lower side of the leaf. Since air temperature inside the small leaf chambers was not controlled, leaf temperature sometimes reached $30^{\circ} \mathrm{C}$ in Experiment 2. Data were recorded on strip-chart recorders and cassette tape which was processed by computer.

In Experiment 1 where the pots with the plants were moved to the laboratory, photosynthesis was measured at a light intensity of about 40 and $160 \mathrm{~W} / \mathrm{m}^{2}(400-$ $700 \mathrm{~nm}$ ) from a bank of SON and HPI lamps (average leaf temperature being about 20 and $23{ }^{\circ} \mathrm{C}$, respectively). In the experiments in the field, measurements were done in situ at natural light intensity supplemented with light from HPLR $400 \mathrm{~W}$ lamps in cloudy periods to ensure light saturation.

\section{Results}

\section{Experiment 1}

The results of the two series of measurements are presented in Table 2. They show that photosynthesis of the youngest fully expanded leaf of the main shoot in intense 
Table 2. Effect of tiller manipulation on photosynthesis $\left(\mathrm{kg} \mathrm{CH}_{2} \mathrm{O} / \mathrm{ha} / \mathrm{h}\right)$ (phot.) at 40 and $160 \mathrm{~W} / \mathrm{m}^{2}$ $(400-700 \mathrm{~nm})$, and resistances $r_{a}+r_{s}$ and $r_{i}(s / c m)$ of the youngest fully expanded leaf of the main shoot in the greenhouse.

\begin{tabular}{|c|c|c|c|c|c|c|c|c|}
\hline \multirow[t]{3}{*}{ Tiller length } & \multicolumn{4}{|c|}{ First series } & \multicolumn{4}{|c|}{ Second series } \\
\hline & \multirow{2}{*}{$\begin{array}{l}40 \mathrm{~W} / \mathrm{m}^{2} \\
\text { phot. }\end{array}$} & \multicolumn{3}{|c|}{$160 \mathrm{~W} / \mathrm{m}^{2}$} & \multirow{2}{*}{$\begin{array}{l}40 \mathrm{~W} / \mathrm{m}^{2} \\
\text { phot. }\end{array}$} & \multicolumn{3}{|c|}{$160 \mathrm{~W} / \mathrm{m}^{2}$} \\
\hline & & phot. & $r_{a}+r_{s}$ & $\mathrm{r}_{\mathrm{i}}$ & & phot. & $r_{a}+r_{s}$ & $r_{i}$ \\
\hline A Medium (dark) & 10.6 & 19.4 & 2.50 & 3.06 & 8.9 & 16.8 & 2.61 & 3.94 \\
\hline B Short & 9.8 & 19.3 & 2.49 & 3.22 & 8.6 & 12.5 & 3.63 & 5.37 \\
\hline C Medium & 9.4 & 15.9 & 3.30 & 3.74 & 8.8 & 11.4 & 4.50 & 5.28 \\
\hline D Long & 8.9 & 12.2 & 4.87 & 4.66 & 7.5 & 8.9 & 7.00 & 6.38 \\
\hline Significant difference* & 0.61 & 1.05 & 0.32 & 0.25 & 0.66 & 1.19 & 0.76 & 0.80 \\
\hline Reproductive & & 18.0 & 3.05 & 3.47 & & & & \\
\hline
\end{tabular}

* According to Duncan's multiple range test.

light is greater when that shoot is accompanied by short tillers than by long tillers. Moreover keeping tillers in darkness stimulated photosynthesis of main shoot leaves as well. With long tillers, photosynthesis was at about the level of vegetative grass in the field, so these tiller manipulations could enhance leaf photosynthesis of these vegetative main shoots to the level of reproductive tillers (data collected in the same period from some vernalized plants) or even higher.

These higher rates of photosynthesis coincided with both a lower gas phase resistance $\left(r_{a}+r_{s}\right)$ and. a lower internal resistance $\left(r_{j}\right)$. Goudriaan \& van Laar (1976) have suggested that $r_{i}$ is decreased by the greater demand for assimilates and $r_{a}+r_{s}$ by the lower internal $\mathrm{CO}_{2}$ concentration. They found that the plants strive for a constant internal $\mathrm{CO}_{2}$ content, so lowering the gas phase resistance and preventing $\mathrm{CO}_{2}$ depletion in case of high $\mathrm{CO}_{2}$ demand.

These results were found at light saturation; at the low light intensity of about $40 \mathrm{~W} / \mathrm{m}^{2}$ there were only minor differences between the treatments. This indicates that the photochemical processes in the leaves proceed at a normal level (Gaastra, 1959), and are hardly affected by the tiller manipulations. The plants with long tillers exhibited only a small increase in main shoot photosynthesis from 40 to $160 \mathrm{~W} / \mathrm{m}^{2}$, in contrast to those in which tillers were shorter or had been kept in the dark where the rate of photosynthesis was increased by 50 to $100 \%$. This might suggest that inhibition of photosynthesis by end-products is more effective at high than at low light intensity.

\section{Experiment 2}

The results of the experiment on spaced plants in the field, presented in Table 3 , show good agreement with the results found in the glasshouse in Experiment 1.

The effects developed in the first week after the treatments were applied and continued to develop during the second and the third week. The greatest increase in photosynthesis occurred in plants on which the greatest stress on the tillers had 
Table 3. Effect of tiller manipulation on photosynthesis $(\mathrm{kg} \mathrm{CH} / \mathrm{O} / \mathrm{ha} / \mathrm{h})$ (phot.) resistances $\mathrm{r}_{\mathrm{a}}+\mathrm{r}_{\mathrm{s}}$ and $r_{i}(\mathrm{~s} / \mathrm{cm})$ and water soluble-carbohydrate (wsc) content (\% of dry mass) of the youngest fully expanded leaf of the main shoot at light saturation in summer 1975.

\begin{tabular}{|c|c|c|c|c|c|c|c|c|}
\hline \multirow{2}{*}{$\begin{array}{l}\text { Treatment and tiller } \\
\text { length (applied } 2 \text { June) }\end{array}$} & \multicolumn{4}{|c|}{ 9-13 June } & \multicolumn{4}{|c|}{ 16-20 June } \\
\hline & phot. & $\mathbf{r}_{\mathbf{a}}+\mathbf{r}_{\mathbf{s}}$ & $\mathbf{r}_{\mathbf{i}}$ & $\%$ wsc & phot. & $r_{a}+r_{s}$ & $\mathbf{r}_{1}$ & $\%$ wsc \\
\hline A Vernalized plant & 15.0 & 3.84 & 5.19 & 20.5 & 18.1 & 3.58 & 3.58 & 28.8 \\
\hline B Short & 24.4 & 1.80 & 2.81 & 16.0 & 22.7 & 2.50 & 2.99 & 18.3 \\
\hline C Short $\rightarrow$ long & 21.5 & 2.20 & 3.08 & 14.5 & 18.2 & 3.52 & 3.27 & 23.3 \\
\hline D Long & 16.4 & 3.02 & 4.25 & 18.8 & 17.0 & 3.65 & 3.84 & 29.9 \\
\hline E Long in darkness & 21.7 & 2.16 & 3.11 & 17.9 & 19.8 & 3.11 & 3.04 & 18.4 \\
\hline Significant difference* & 2.04 & 0.46 & 0.64 & & 2.06 & 0.47 & 0.76 & \\
\hline
\end{tabular}

* According to Duncan's multiple range test.

been imposed by repeated cutting. It also appeared that this improvement diminished when the stress decreased, as in treatment $\mathrm{C}$ which had longer tillers in the third than in the second week.

Unfortunately stem elongation had not yet occurred in the vernalized plants when measurements were made, so it is not surprising that they established the same photosynthesis as the non-vernalized plants with the long axillary tillers.

The data on the water-soluble carbohydrate content show a fair negative correlation with photosynthesis, which agrees with the data of Behaeghe (1975) who found higher growth rate and lower soluble carbohydrate contents in vernalized than in non vernalized Lolium perenne and Dactylis glomerata. This may suggest that a high soluble-carbohydrate content inhibits photosynthesis, but it is more likely that in the untreated plants both the lower photosynthesis and the higher solublecarbohydrate content are the result of a smaller demand for assimilates.

\section{Experiment 3}

The results of this experiment are presented in Table 4, which shows that only in

Table 4. Effect of tiller manipulation on photosynthesis $\left(\mathrm{kg} \mathrm{CH}_{2} \mathrm{O} / \mathrm{ha} / \mathrm{h}\right)$, resistance $\mathrm{r}_{\mathrm{a}}+\mathrm{r}_{\mathrm{s}}, \mathrm{r}_{\mathrm{i}}(\mathrm{s} / \mathrm{cm})$ and water-soluble carbohydrate content ( $\% \mathrm{wsc})$ of the youngest fully expanded leaf of the main shoot at light saturation in autumn 1975.

\begin{tabular}{|c|c|c|c|c|c|c|c|c|}
\hline \multirow{2}{*}{$\begin{array}{l}\text { Treatment and tiller } \\
\text { length (applied } 8 \text { Sept). }\end{array}$} & \multicolumn{4}{|c|}{ 15-19 September } & \multicolumn{4}{|c|}{ 22-26 September } \\
\hline & phot. & $r_{a}+r_{s}$ & $r_{i}$ & $\%$ wsc & phot. & $\mathbf{r}_{\mathbf{a}}+\mathbf{r}_{\mathrm{s}}$ & $\mathrm{r}_{\mathbf{i}}$ & $\%$ wsc \\
\hline A Heavy crop & 11.0 & 4.25 & 8.05 & 24.9 & 7.6 & 6.29 & 11.15 & 21.9 \\
\hline B Short & 12.8 & 3.31 & 6.20 & 24.0 & 15.2 & 3.56 & 4.51 & 23.7 \\
\hline C Short $\rightarrow$ long & 12.6 & 3.83 & 6.13 & 23.7 & 14.0 & 4.12 & 5.28 & 25.5 \\
\hline D Long & 11.9 & 3.53 & 5.77 & 26.4 & 12.7 & 4.29 & 5.72 & 26.4 \\
\hline $\mathrm{E}$ Long in darkness & 13.7 & 4.31 & 7.00 & 27.2 & 16.7 & 3.16 & 4.78 & 22.6 \\
\hline Significant difference* & 1.81 & 0.63 & 1.69 & & 1.38 & 0.73 & 1.22 & \\
\hline
\end{tabular}

* According to Duncan's multiple range test. 
the 3rd week after establishment of the treatments significant effects were found. This is not surprising since the plants were almost without axillary tillers in this well fertilized and well irrigated field and the measured leaves still had been formed in sward conditions. Since those tillers were not present they could not be put under clipping stress and so photosynthesis could not be enhanced. However in the third week some enhancement of photosynthesis of the youngest fully expanded leaf was found. Presumably this was because in the spaced plant position the shoots had formed some tillers which were clipped or exposed to darkness, and the measured leaves were formed in brighter conditions. The data on net photosynthesis of the leaves in the crop position were the lowest, possibly because they were developed in a poor light environment as was found by Leafe et al. (1974) and Prioul et al. (1975), and they agree very well with those of former trials in autumn (Deinum, 1972; 1973; unpublished data). As in Experiment 2 there was a fair negative relationship between photosynthesis and \% water-soluble carbohydrate in the spaced plants during this week. Of course, the leaves from the crop did not fit in this relation: they were lower in soluble carbohydrate since they were exposed to lower light intensity due to mutual shading before the photosynthesis measurement.

From the results of this experiment it is clear that in autumn as in summer, leaf photosynthesis can be improved appreciably, and even doubled, by manipulation of environmental conditions and by putting a stress on the axillary tillers.

\section{Discussion}

The results of these experiments agree very well with those of Gifford \& Marshall (1973) with spaced plants of Lolium multiflorum, in which defoliation of axillary tillers stimulated photosynthesis of the young and older leaves on the main shoot. However, unlike to our experiments, this better photosynthesis was only attributable to a lower stomatal resistance. These results also agree with those of Davies (1974) who found hardly any negative effect of partial defoliation on relative growth rate. Apparently the remaining leaf area was sufficiently capable of supplying the plant with the sufficient assimilate to maintain growth rate.

There is also a good agreement with the results of Woledge (1973) and Woledge \& Leafe (1976) who found that in a vegetative grass crop in summer and autumn, maximum photosynthesis of the youngest adult leaf declined with the age of the crop, but remained almost constant in spaced plant conditions. Photosynthesis at light saturation might even improve if plants were changed from crop to spaced plant conditions. The same is apparent from Table 4, which shows that leaf photosynthesis in the crop situation was much lower in the third than in the second week, whereas in the spaced plant condition the reverse occurred. This low photosynthesis in the heavy crop may be caused by the poor conditions during development of the leaf and the high photosynthesis in spaced plant by better conditions during leaf development and the greater demand for assimilates. This explains also the results found in Dactylis glomerata in the USA (Deinum, 1968), which show low levels of photosynthesis in young leaves of an old crop but extremely high levels in the first developed leaves of the regrowth after cutting. 
One might suggest that the light environment of the main shoot improved by defoliation of the axillary tillers and so enhanced photosynthetic capacity of the developing leaves on the spaced plants. However light intensity during the experiments was so high and mutual shading of the tillers so small that light intensity at the plant base hardly can be increased.

All these data indicate that photosynthesis can be modified appreciably, whereas the rather large standard errors (viz. significant differences) denote the great intra plant variation in photosynthesis in our experiments. This may be caused by a great phenotypic variation in root and stubble weight and in the profuseness of tillering. In relation to research on the improvement of photosynthesis, this suggests that variability may be caused by variability in demand for assimilates. Stems and infloresences can function as a sink and if a grass crop should produce stems and infloresences not only in spring, but also later in the season it may be possible to obtain higher yields. Moreover light is penetrating better into the lower regions where leaf development is occuring in such crops. Thus the high yield Cooper (1972, personal communication) obtained from two genotypes is possibly due to their stem formation in both the first and the second cutting.

Root and stubble can also function as a sink for assimilates. Thus Darwinkel (1976) found that a newly sown grass was more productive than an old sward, as a result of a much greater production of stubble and root. So with a smaller quantity of leaves a greater amount of dry matter was produced in the new sward.

Woledge's experiments and ours suggest that there is potential for higher photosynthetic capacity in grass leaves in vegetative crops in the autumn. This potential could be exploited by the creation of sinks, for example stems. If such stems are formed then light penetration into the crops is improved, and consequently photosynthetic capacity of the leaf. Higher yields may then be attained, but it is certain that such a sward will need a longer regrowth period since the growing points will be removed by cutting and grazing. Moreover it may be less persistent and more susceptible to investations by weeds. In addition stems are not favoured in ruminant nutrition since they are less digestible and less palatable especially when old.

Another possibility for a greater utilization of available solar radiation in late summer and autumn might be found in crops in which the stems have a large storage capacity for soluble carbohydrates as in sugar cane and maize. Such crops may need the whole growing season for maximum yield, and hence will not be suitable for grazing.

So in conclusion it can be stated that the poor production of a grass crop in late summer and autumn is a concommitant of low photosynthetic efficiency of the individual leaves which in turn is caused by a small demand for assimilate and by unfavourable conditions during leaf development. Thus, although it is possible, by tiller manipulation, to increase leaf photosynthesis in vegetative grass crops in the autumn, it is not clear at the present time how these findings can be used in farm practice to increase herbage production. 


\section{Acknowledgment}

The author wishes to thank Mr Johan Knoppers for assisting in running the experiments and in the calculations, whereas the comments of $\mathrm{Dr}$ Th. Alberda (Centre of Agrobiological Research, Wageningen) and Dr E. L. Leafe (Grassland Research Institute, Hurley, England) are greatly appreciated.

\section{References}

Alberda, Th., 1974. Invloed van seizoen en leeftijd op de fotosynthese van een gesloten zode. Gebundeld Versl. Ned. Ver. Weide- en Voederbouw 13: 77-84.

Alberda, Th. \& L. Sibma, 1968. Dry-matter production and light interception of crop surfaces. III. Actual herbage production in different years compared with potential values. J. $B r$. Grassld Soc. 23: 206-216.

Behaeghe, T. J., 1974. Experiments on the seasonal variations in grass growth. Proc. 12th int. Grassld Congr. (Moscow): 268-281.

Behaeghe, T. J., 1975. Eco-fysiologische grondslagen van de grasgroei. Agricultura 23: 19-45.

Clifford, P. E., C. Marshall \& G. R. Sagar, 1973. The reciprocal transfer of radiocarbon between a developing tiller and its parent shoot in vegetative plants of Lolium multiflorum Lam. Ann. Bot. 37: 777-785.

Davies, A. G., 1974. Leaf tissue remaining after cutting and regrowth in perennial ryegrass. J. agric. Sci. Camb. 82: 165-172.

Deinum, B., 1968. Measurement of forage quality and achievement of maximum crop production. Gestencilde Meded. Afd. LandbPlTeelt GraslCultuur 15: 28.

Gaastra, P., 1959. Photosynthesis of crop plants as influenced by light, carbondioxide, temperature and stomatal diffusion resistance. Meded. Landbhogesch. Wageningen 59-13; 68 pp.

Gifford, R. M. \& C. Marshall, 1973. Photosynthesis and assimilate distribution in Lolium multiflorum Lam. following differential tiller defoliation. Aust. J. biol. Sci. 26: 517-526.

Goudriaan, J. \& H. H. van Laar, 1976. Measurement of some relations between leaf resistance, $\mathrm{CO}_{2}$-concentration and $\mathrm{CO}_{2}$-assimilation in maize, beans and sunflower. (Submitted to Photosynthetica.)

Leafe, E. L., 1972. Micro-environment, carbon dioxide exchange and growth in grass swards. In: A. R. Rees et al. (Ed.), Crop processes in controlled environment, pp. 157-174. Academic Press, London/New York.

Leafe, E. L., W. Stiles \& Sara E. Dickinson, 1974. Physiological processes influencing the pattern of productivity of the intensively managed grass swards. Proc. 12th int. Grassld Congr. (Moscow): 442-457.

Prioul, J. L., A. Reys \& P. Chartier, 1975. Relationship between carbondioxide transfer resistances and some physiological and anatomical features. In: R. Marcelle (Ed.), Environmental and biological control of photosynthesis, pp. 17-28. Junk, The Hague.

Woledge, J., 1973. The photosynthesis of ryegrass leaves, grown in simulated swards. Ann. appl. Biol. 73: 229-237.

Woledge, J. \& E. L. Leafe, 1976. Single leaf and canopy photosynthesis in a ryegrass sward. Ann. Bot. 40: 773-783. 